\title{
How to Manage Perception to Win Negotiations
}

\author{
Katarzyna Jagodzinska ${ }^{1}$ \\ ${ }^{1}$ Enterprise Institute, University of Neuchâtel, Switzerland \\ Correspondence: Katarzyna Jagodzinska, Enterprise Institute, University of Neuchâtel, Rue A.-L. Breguet 2, CH-2000 \\ Neuchâtel, Switzerland.
}

Received: January 4, 2016

Accepted: January 19, 2016

URL: http://dx.doi.org/10.11114/ijsss.v4i2.1320

\begin{abstract}
Perception management is undeniably one of the critical skills of a master negotiator. While the idea that negotiators should control how their counterparts perceive them has already been examined in literature, there does not exist a strategic model for applying perception management into modern negotiation practice. This article indicates how negotiators can manage how they see themselves and how they feel in ways that can influence others' perceptions of them, in order to increase their inner bargaining power and consequently win negotiations. In view of the above, I introduce the 3-Dimensional Model of Perceptual Management in Negotiation. The model provides a straightforward and user-friendly framework that can be used to prepare for a negotiation or at any time during a negotiation to boost the chances of a successful outcome.

Furthermore, this article provides a comprehensive overview of the perceptual process, explains the impact of perceptual selection on negotiation and presents the most common attribution errors. Since perception depends to a large extent on individual inclinations, the article is garnished with visualizations of the theoretical aspects designed for all those to whom images speak louder than words.
\end{abstract}

Keywords: negotiation, impression management, bargaining power, perception, perceptual selection, attribution errors, verbal and non-verbal communication.

1. Introduction

One of the essential skills of a master negotiator is the ability to read people in order to recognize their needs and anticipate their next move based on what they crave to achieve. The way a person behaves, both consciously and unconsciously, is very revealing. Decoding the real message behind their verbal and non-verbal communication is a valuable source of information, which can then be used as powerful tool of influence. Sooner or later we will all have to face a negotiation that may be life changing for us, whether in a professional or personal setting. Its outcome will depend on how well we have trained ourselves in the art of perception management. Practice makes perfect. It is thus helpful to develop the necessary skills on a continuous basis and not just ad hoc when we need to prepare for an upcoming negotiation. Fortunately, people watching and uncovering individual preferences has never been easier than it is now.

The most inspiring professor I ever had at University once said that life is a theatre. Sitting at one of the airports during my frequent travel, I came to the conclusion that only the setting changes, the actors are busy doing pretty much the same thing wherever one happens to go. Everyone seems preoccupied with checking emails, chatting online or whatever else activity they can think of with the use of mobile devices and the Internet. A vast majority is fully devoted to taking pictures of themselves - the so called "selfies". These selfies are then posted on Instagram, Facebook or any other social network, and shared with the rest of the world. It would seem that people have an urge for showing off their perceived individualism and importance. As I pondered about my observations, the term "selfie generation" came to my mind. It depicts a generation of self-centered individuals governed by the need to exhibit their lifestyle, social status, achievements, activities, and ultimately to feed their egos. My next thought was how this translates into modern business practice, specifically what are the implications for negotiation.

According to Cohen, negotiation is a field of knowledge and endeavor that focuses on gaining the favor of people from whom we want things (Cohen, 1980). As observed by Fisher, Ury and Patton, negotiation is about much more than merely obtaining support or preferential treatment from the other party: Negotiation is a basic means of getting what you want from others. It is a back-and-forth communication designed to reach an agreement when you and the other side have some interests that are shared and others that are opposed (Fisher, Ury \& Patton, 2012).

In a negotiation thus what is important is to understand individual particularities in order to reach a mutually acceptable agreement on how to satisfy the needs and interests of both negotiation partners. Needs and interests are rarely explicitly voiced and more information is transferred through non-verbal rather than verbal communication. 
Consequently, the importance of managing the impressions one makes takes on a new dimension. Perception management operates on two levels. Firstly, we want to understand with whom we are dealing, what are this persons' hot buttons as well as the motivational factors that drive this person and, in consequence, what is important for him or her. This knowledge will enable us to find creative options for mutual gain in the face of a negotiation. Secondly, we want to be in full control of what we ourselves reveal to the other party both through our verbal and non-verbal behavior. Going back to the observation on the selfie generation, perhaps people have always been as self-oriented as they are now, but modern technology makes it so much easier to investigate their needs and interests, which in turn helps predict the negotiation positions they may assume. In order to fully grasp the implications of managing perceptions on the negotiation process, it is vital to increase awareness about the major elements forming the perceptual process, raise understanding about what perception management is, as well as uncover how the attribution process works. All the above elements will now be addressed in more detail and seasoned with real life examples from my own negotiation practice.

\section{The Perceptual Process: Managing Emotions and Framing}

Perception is a six-step process during which the individual observes, selects, organizes, interprets and responds ${ }^{1}$ to a perceptual trigger: the source of information (situation, object, person), as illustrated in Figure 1 (Slocum \& Hellriegel, 2011).

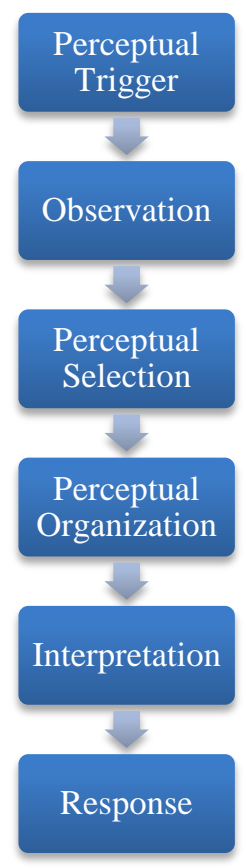

Figure 1.

It is the perception of reality and not reality itself that influences individuals' behavior. People's reactions are based on their subjective perception of reality, consisting of a situation, object and/or the other person. The person who is "being perceived" is in turn also acting based on his or her perception of the context (situation, object and/or person). I will explain this process on the example of an experience I recently had. During a particularly busy work schedule I was lecturing in three countries over a period of one week: Poland, France and Switzerland as the final destination. In Switzerland I pulled into a gas station to refill the tank and wash my car. Next to the station was a used car dealership. Waiting for the cycle to finish I wandered over there to take a look at the vehicles on offer. I spotted the sales person through the window of his office; he briefly looked up but did not pay much attention to me. As I was walking around the lot where the cars were parked one of them particularly caught my eye. The model, color, production year, extras and mileage all seemed very attractive. To my surprise the price was extremely reasonable in relation to the value of the car. Suddenly, very animated, I started inspecting it from all angles. Because I liked the machine so much, in my mind's eye, I started to consider exchanging it for my own car. I excitedly took out my cell phone to consult this rather

\footnotetext{
${ }_{1}^{1}$ Adopted from: John W. Slocum, Don Hellriegel, Principles of Organizational Behavior, 13th edition, South-Western Cengage Learning, 2011, p. 105.
} 
spontaneous idea with my friend. Just as I was about to dial I saw the sales person approaching me. Suddenly his demeanor was much different than when he first saw me through his office window. With a big smile on his face, he was pacing my way with his hand extended to greet me. We exchanged the typical pleasantries. He started his sales talk advertising the car and all it had to offer. Still very much excited, I listened with bright eyes occasionally nodding my head. I then made my call. He discretely turned away and stood at a distance to allow me some privacy while I talked. I described the situation to my friend, presented the car features and went on to stating the great price. My friend's question was like an accepted ice bucket challenge: "Which currency?" These two words completely changed my perception of what I up to then perceived to be the reality: a very attractive price for a fancy car. In the fervor of the moment and too tired to realize I have been travelling to countries with different currencies it slipped my mind that the price for the car was indeed in Swiss francs. No longer so attractive if compared to the Polish currency I had encoded in my head! ${ }^{2}$

When I hung up, the salesman turned back to me with budding hope for securing his commission. The change in dynamics was unmistakable though. Feeling a bit overwhelmed I thanked him and quickly made my way back to my own car.

Let us now analyze each of the 6 elements of the perceptual process on the basis of the above adventure. The perceptual trigger in this case was an object. While walking around the car dealership arena I entered the phase of observation during which I performed a preliminary perceptual selection of one car that caught my eye. Having made a visual assessment of all the other vehicles on display (mark, model, size, color, mileage, extra features, etc.) I then proceeded with the perceptual organization: I compared their prices and contrasted them with the knowledge I had about market prices for similar used cars. Based on this analysis I made the following interpretation: the vehicle that I liked most was both desirable and affordable for me. My response was to consider exchanging my own car for it, and to call and consult my friend about this bold move.

I would like to uncover the dynamics behind the perceptual process and specifically to point out the impact of perception(s) on bargaining power in negotiation. When I first entered the car dealership my demeanor was completely neutral. I was bored and decided to distract myself by looking at cars while my own one was being washed. The sales person who spotted me through his office window reacted to me accordingly to his own perception. He saw me as a random visitor and therefore not someone who would merit his attention, energy and time. If this were a negotiation my bargaining power would have been on level zero. Due to a perceptual mistake on my part (confusion about currency and exchange rates), I led myself to believe that I spotted a very lucrative deal. In consequence my whole attitude changed. Enlivened I walked around and inspected the chosen car with great confidence in my stride. I went from neutral to level one, as would have my bargaining power had this been a negotiation. The shift certainly attracted the attention of the sales person. He started to perceive me as a potential client and decided to make the effort and leave his desk and approach me with distant hope of closing a sale. When I completed my scrutiny of the car I began considering the exchange of cars in my mind. The sales person perceived this as his "now or never" moment and started giving me his best sales talk to convince me about the deal. My bargaining power would have been at its peak at that stage. The consulting call to my friend caused it to hit rock bottom though.

How does this translate into negotiation? Due to my response to a perceptual trigger I caused the change in the perceptual process of the sales person and in turn altered his attitude towards me. In a negotiation I would have managed to achieve a high on bargaining power despite an erroneous analysis on my part. Each person can learn how to exercise command over their own perceptual process: the observation, selection, organization, interpretation and response to a perceptual trigger. This realization can seriously boost the chances of winning a negotiation. By programing the mind into believing something we can start by improving our mental BATNA (Best Alternative to a Negotiated Agreement), which in turn leads to the increase of bargaining power and favorably influences how others perceive and act towards us. The simplified process is illustrated in Figure $2^{3}$.

\footnotetext{
${ }^{2}$ CHF/PLN= approximately 4,064 (as of January 2016)

3 Author's own concept and illustration.
} 


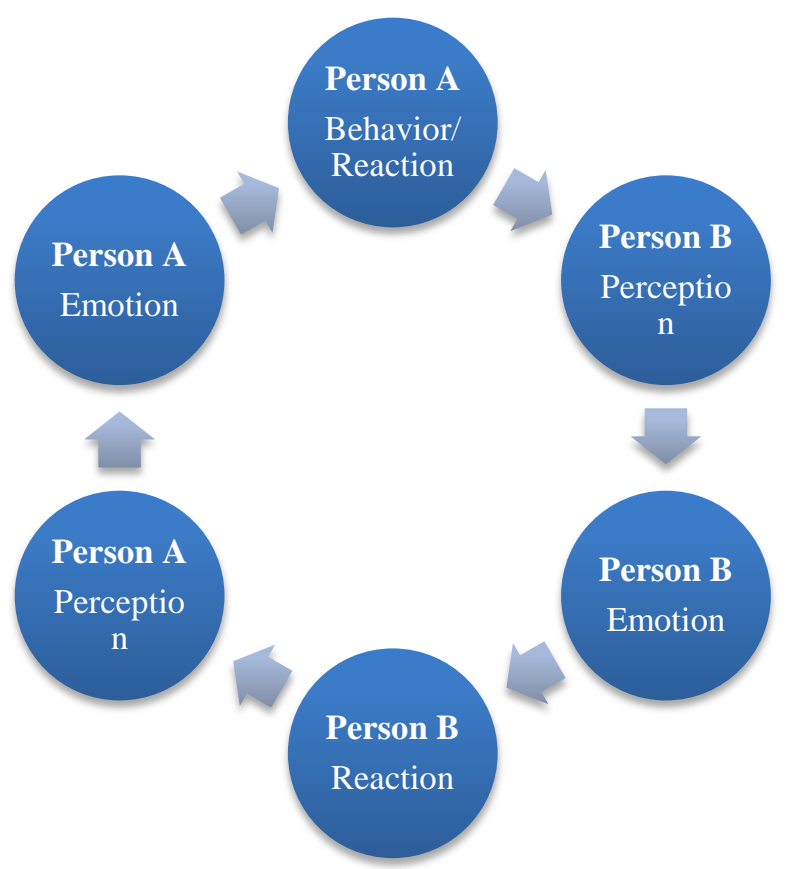

Figure 2.

In the above diagram there appears one crucial element that merits attention: emotions. Emotions are the flame of negotiation and as such a considerate amount of research has been dedicated to the topic. As Fisher and Shapiro rightly observed, "Emotions can be obstacles to negotiation (...). They can divert attention from substantive matters; they can damage a relationship; they can be used to exploit you." (Fisher \& Shapiro, 2006). Regardless of their destructive potential, emotions cannot and should not be switched off though. They are the indicators of what we find acceptable and what not, they are our inner GPS system. In the prequel to Getting to Yes, Ury argues that learning and understanding our own emotions is the key to influencing ourselves first; only then can we attempt to impact others (Ury, 2015). The book advertises itself as "The First Step in Any Negotiation, Conflict or Difficult Conversation". Without a doubt this is a catchy marketing phrase, but content wise only partially true. As shown above, emotions do not just randomly happen, they are triggered by perceptions, which only then transform them into feelings of threat, anger, injustice and a whole array of other sentiments. "Getting to yes with yourself" thus starts not only by learning how to control one's own emotions in order to persuade others, but more importantly, by taking over the perceptual process, which causes the flow of these emotions.

A critical aspect in perception management and negotiation is framing. A frame is the subjective lens through which people see the world, which affects how they organize information, evaluate situations and what actions they consequently take $\mathrm{e}^{4}$. Because of a spectrum of individual differences, backgrounds, life experiences, expectations, wants and fears, each person frames reality in a unique way. The authors of "Difficult Conversations" refer to this phenomenon as simply having "different stories". These stories come from several sources: available information, our observations, our interpretations and our conclusions (Stone, Patton \& Heen, 1999). Both parties notice different things based on the information they selectively pay attention to. Interpretations made on the basis of selective screening are impacted by past experiences, as well as by the application of different implicit moral rules and standards. Very often, people develop self-serving biased perceptions: they focus on what they want to believe and reject all information that does not fulfill this purpose. Not surprisingly, the conclusions then reached are often one sided and mirror one parties' self-interest only.

The traditional approach to perception in negotiation implies that there are at least two parties whose perceptions differ. These divergences then shape the negotiation dynamics. At first glance the used car anecdote I described above does not seem to fit this framework since it relates only to my omission in taking into account one of the elements of the perceptual trigger: the currency. But the mistake I made is precisely my own, personal story: my observation of the situation, my interpretation of the information and my conclusions. The simplified example proves that even an erroneous assumption can set the wheels of the perceptual process into motion and alter not only one's own story, but also impact the story (and behavior) of the person with whom we are dealing with. More importantly, at the outset

\footnotetext{
${ }^{4}$ For more information see: R. J. Lewicki, D. M. Saunders, B. Barry, Essentials of Negotiation, 5th ed., McGraw Hill, 2011, p.
} 115-122. 
perception in negotiation does not require the involvement of two parties. Initial one-sided perception frames reality and evokes certain emotions, which are then reflected in behavior. The other party perceives the situation and reacts accordingly to this framing. Managing one's own perception can thus be used as powerful tool of social influence.

\section{The Impact of Perception Management on Negotiation}

We live in an era of technology overload. Information is bombarding us from all angles. As we get ready for work news headlines compete for our attention, the radio broadcasts more commercials than music, emails, texts and instant messages keep flooding our computer and portable devices; while our family tries to communicate with us. We become immune to most of this noise and focus on the task directly at hand. To remain sane, the brain has to manage the intelligence. It does so by selective screening - filtering of information in order to deal only with the most important matters. Selective screening is governed by external and internal factors. The former are characteristics of the person being perceived and the latter are characteristics of the perceiver.

Person perception is a three-dimensional process by which the individual attributes characteristics or traits to other people. It is shaped by the external and internal factors, as well as the situation or context within which perception takes place. External features of the perceived are, among others, age, posture, gender, voice quality, facial expressions, attributes of social status and role, etc. These are the elements we immediately notice about the other person. Based on our observations we make preliminary judgments, categorize the person and make plans about how to deal with him or her. By means of a simplified example, we may view a smartly dressed male in his mid-40's, with a straight posture and a hard look in his eyes, speaking in a confident and strong voice as someone who might be a seasoned and no-nonsense negotiator. Morgan Wright, an 18-year veteran of law enforcement who has trained CIA, FBI and NSA agents in behavior analysis, interviewing and interrogation techniques, calls this "command presence" - the look of authority 5 According to Wright, "As an officer you can invite trouble if you slouch, avoid eye contact, use vague, imprecise language, and are generally sloppy in your attire."6 Clearly there is a difference between dealing with criminals and entering the negotiation zone. But the point is clear: people make judgments based on their perceptions, which are to a large extent based on how you look and behave.

Characteristics of the perceiver fall into the following three categories: personality, learning and motivation ${ }^{7}$. These internal features predetermine how one interprets reality based on his or her present state of being, as well as past similar experiences which have a bearing on the way the individual will behave in similar future circumstances (the so called perceptual set). I call this phenomenon the system of pertinence of an individual. With reference to the selfie generation, it can best be described as a snapshot of a person's life at a given moment. Such a photograph would depict all the preoccupations, motivations, dreams, fears, joys, hopes, etc. linked to the past that shape how the person sees himself, others and the world at a given moment. In relation to negotiation it is vital to "know why the fish swim" (Thompson, 2008), to understand individual differences (the internal factors) and their affect on how the person with whom we are dealing with views the environment (translation into external factors). The last element forming the perceptual puzzle is the situation or context within which perception takes place. Imagine for example that you have prior exposure working in foreign countries, negotiating across-cultures or dealing with multinational parties. The element of diversity will not sway your bargaining power in the face of a multicultural negotiation. Furthermore, your international experience will also allow you to better comprehend the characteristics of the perceived in order to better manage the relationship and communication process.

Selective screening plays a big part in the negotiation process. We pay attention to certain aspects (our needs, interests and positions) while blocking out the background noise. As already shown, a person's selection process involves both external and internal factors. The individual then organizes these stimuli into meaningful patterns. People perceive the same things in different ways, and their behaviors depend, to a large extent, on their individual perceptions. When raising the topic of perception in negotiation the typical attribution people make is that of two parties having a different perception of an object, as shown in Figure $3^{8}$.

\footnotetext{
${ }^{5}$ For more information see: Carmine Gallo, Talk Like Ted. The 9 Public Speaking Secrets of the World's Top Minds, Macmillan, 2014, p. 90.

${ }^{6}$ Cited in: Carmine Gallo, Talk Like Ted. The 9 Public Speaking Secrets of the World's Top Minds, Macmillan, 2014, p. 90

${ }^{7}$ There exist extensive studies on motivation, learning and personality, and as such these notions will not be covered in detail in this article.

${ }^{8}$ Author's own concept and illustration.
} 


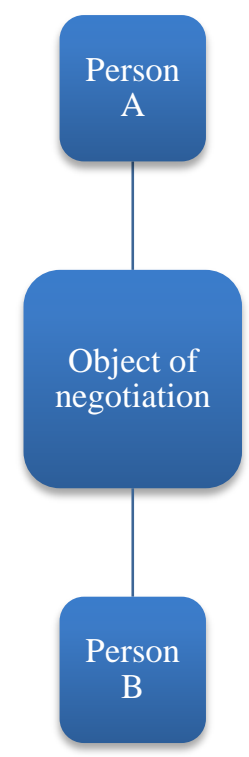

Figure 3.

The object may be any matter that is at the heart of the negotiation: the division of available resources, agreeing on a price, reaching a mutually satisfactory outcome to an agreement, finding a resolution to a difficult situation, etc. The object may be "the reality" but both person A and B have different perceptions of what that reality, consisting of a situation, object and/or the other person, in fact means.

\section{The 3-Dimensional Model of Perceptual Management in Negotiation}

The standard approach to perception in negotiation presented in Figure 3 fails to take account of two aspects: the situational context and the impact of individual perceptions on one's own conduct, which in turn triggers a reaction of the other party. I therefore find it vital to introduce the 3-Dimensional Model of Perceptual Management in Negotiation (the 3-D Negotiation Model), illustrated in Figure $4^{9}$.

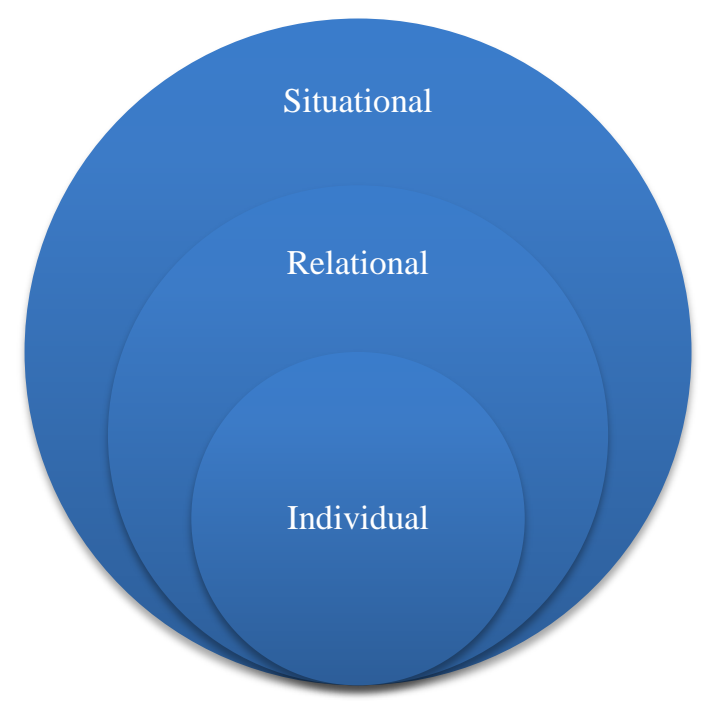

Figure 4.

The point that negotiators can manage how they see themselves and how they feel in ways that can influence others' perceptions of them has already been raised in literature. However, studies do not provide a specific tool that negotiators could use to master the art of perceptual management in negotiation, a niche that the introduction of the 3-D Negotiation Model aims to fill. The model comprises the trio of individual, relational and situational perception. At the core of the 3-D Negotiation Model lies the unique perception each person makes, which starts the six-step process

\footnotetext{
${ }^{9}$ Author's own concept and illustration.
} 
during which he or she observes, selects, organizes, interprets and responds to a perceptual trigger. As discussed earlier, this mechanism is governed by internal and external characteristics. Individual perception influences how others see and react to us. Consequently it has a bearing on the relational element: the nature and rules governing the relationship with the party we are dealing with. Individual and relational dynamics then define the approach of parties A and B to the negotiation object. The situational context is the continuum of all these elements reflected in the negotiation strategy, style, tactics employed, etc.

Over the past few years I have developed and applied the 3-D Negotiation Model in my private negotiation endeavors and have taught it to my students and business clients. Many have admitted that the model opened their eyes to certain dynamics, either caused by their own behavior or the conduct of the other party, which have, usually adversely, affected their bargaining power. The model made them realize what was the elusive element that was often causing their negotiations to go astray. Post factum analysis of the model has made them understand and take command over the perceptual process, and adjust their negotiation strategy accordingly. Furthermore, it has helped them raise awareness about the individual, relational and situational perception elements that might come into play in any future negotiation ${ }^{10}$. The most important realization drawn from the 3-D Model is that the starting point of perceptual selection, which determines the outcome of any negotiation lies within. Each person can learn how to exercise command over their selective screening, for example by focusing on boosting one's confidence and mental BATNA while blocking out the background noise, such as anxiety, nervousness, self questioning and doubting in one's bargaining power. A self-conscious attitude, inner stability and air of control will certainly not go unnoticed by the other party who will adjust their behavior accordingly. According to Amy Cuddy, a social psychologist at the Harvard Business School who conducts research into body language, posture and nonverbal behavior shape who we are. She says that "how we use our bodies - our nonverbal cues - can change people's perceptions of us. (...) simply changing your body position affects how you feel about yourself and, by default, how others see you" (Gallo, 2014). ${ }^{11}$

Many authors share the view that preparation is the condition sine qua non of a successful negotiation ${ }^{12}$. Solid preparation notably implies the management of the perceptual process of oneself and in this way influencing the perception of the other party. This is the pre-step of convincing the other party to our logic, which reflects our needs and interests. Adopting such an approach will help to navigate through any negotiation, be it with a "difficult" person or with a, presumably, much stronger opponent.

By means of introduction of the 3-D Model I thus arrive at the refined definition of negotiation: it is a process of perceptual self-management during which two parties with common and opposing needs and interests, try to reach a mutually acceptable agreement, which harnesses the needs and interests of both sides.

\section{Common Attribution Errors}

The attribution process is the way that people make sense of the causes of their own and other's behavior. It consists of three elements: antecedents, attributions and consequences, as visually presented in Figure 5 (Slocum \& Hellriegel, $2011)^{13}$. Antecedents are the factors internal to the perceiver, such as the amount of information he or she has about the other party and the overall situation, as well as the perceivers' beliefs and motivation. Based on these factors, the perceiver makes attributions about the presumed cause of behavior of the person being perceived. The assigning of cause leads to consequences, which are reflected in certain behaviors, feelings and related expectations.

\footnotetext{
${ }^{10}$ According to the testimony of the participants of my trainings conducted in the following companies: Dassault Systemes (Paris, France), Celgene (Boudry, Switzerland) and Unilever (Katowice, Poland).

${ }^{11}$ To watch Amy Cuddy's TED talk Your Body Language Shapes Who You Are go to:

https://www.youtube.com/watch?v=Ks-_Mh1QhMc (as of 29.04.2015)

${ }^{12}$ For example: Leigh Thompson, The Truth about Negotiations, Pearson Education Ltd, 2008, p.8-9; G. Richard Shell, Bargaining for Advantage. Negotiation Strategies for Reasonable People, Penguin Group, 2006, p. 120.

${ }^{13}$ Adopted from: John W. Slocum, Don Hellriegel, Principles of Organizational Behavior, 13th edition, South-Western Cengage Learning, 2011, p. 121.
} 


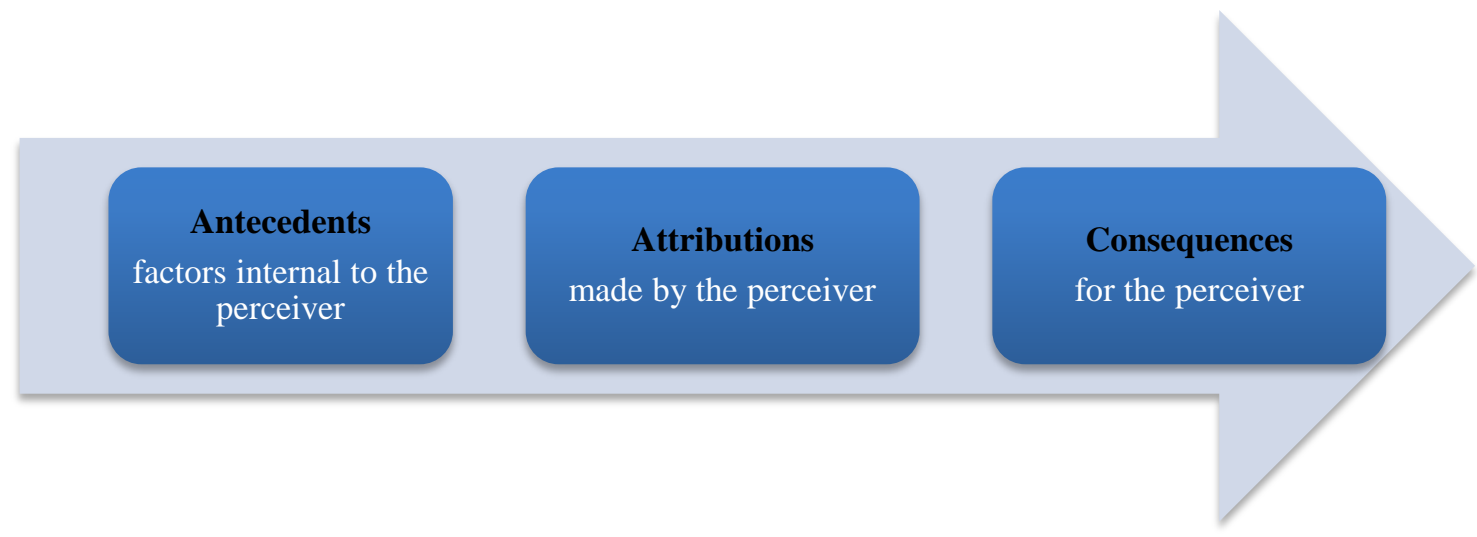

Figure 5.

The attribution process is highly subjective because it is primarily governed by the factors internal to the perceiver; the margin of error in correctly comprehending the causes of behavior is therefore quite substantive. I will briefly present the most common perceptual mistakes and highlight the impact that they might have on the negotiation process. Achieving perceptual accuracy is a challenge in itself. Similarity, contrast or first impression errors may adversely affect the cause (attribution) and effect (consequences) relationship. Earlier we discussed the selective screening process. While it is inevitable (and often recommended) to filter the flow of information, excessive selective screening leads to perceptual defense, defined as hearing only what we want to hear. Studies have shown that the human brain processes positive events and data much more accurately than negative ones (the so called Pollyanna Principle). The danger related to perceptual defense is that one might fail to grasp the broad picture when negotiating, especially when dealing with a party who can sweet talk into a deal. As a safeguard it is essential to carefully balance the good aspects with the less favorable ones. Another common perceptual error is stereotyping, that is assuming that all members of a particular group share the same features, traits or behaviors. In the era of internationalization of business conduct, not only is this offensive, but also limits the ability to fully comprehend and craft creative solutions based on individual differences and resulting preferences. On the other hand, projection - an error consisting in assigning one's own traits to the other person may equally cloud our judgment of the person with whom we are dealing with, which in turn may cause us to let our guard down, and in consequence negatively impact the negotiation process. Quite an interesting perceptual mistake is the phenomenon referred to as the halo effect, which I like to call the "devil or angel impression". It occurs when one positive or negative characteristic dominates the way a person is perceived. As shown on the example of the negotiation simulation, the way we perceive someone radiates through us and ultimately impacts our behavior toward that individual. If the dominant taste that we have is rather bitter, then we run the risk that our concern with the negativity may adversely affect the relational dynamics with the other party and ultimately ruin the whole situational framework. A positive halo effect is equally risky because it may make us more prone to giving in to unreasonable demands or making concessions based on pure sympathy rather than logic and fair standards.

In order to avoid falling into one of these attribution traps it is first and foremost recommended entering a negotiation with the awareness of existence of perceptual biases, while equipping oneself with knowledge about how the perceptual process works for both parties.

\section{Conclusion}

The perceptual process consists of six steps during which the individual observes, selects, organizes, interprets and responds to a perceptual trigger. By introducing the 3-Dimensional Model of Perceptual Management in Negotiation this article re-examines the established concept of achieving success in negotiations. The practical application of the 3-D Negotiation Model demonstrates that negotiation is about much more than merely obtaining support or favorable treatment from the other party. It is no longer purely about needs and their fulfillment or arriving at a mutually acceptable agreement with the other party. Taming emotions and achieving excellence in conveying them do not suffice either. One of the vital steps in the modern approach to negotiation consists of impression management: firstly taking command over the perception a person has of oneself, and then using this control to influence how other's perceive and act towards us. This realization is fundamental in breaking away from the mental constraints that all too often cause us to fail in negotiations or impede our full potential. By programing the mind into believing in our inner strength and not allowing others to sway this conviction by their verbal or non-verbal communication, we can considerably increase our actual bargaining power.

Raising awareness about the most common attribution errors and how they can cloud the perceptual process helps shield 
against the typical perceptual biases. In addition to that, employing critical thinking and exercising sound judgment based on the analysis of the trio of individual, relational and situational dynamics presented by the 3-D Negotiation Model can greatly enhance the chances of reaching a fair, efficient and mutually beneficial negotiation outcome. Last but not least, knowing and taking control of self- perception is a prerequisite to substantive preparation.

Perceptual self-management and exercising command presence take practice and time, and as such cannot be performed on a just-in-time basis when we need to prepare for a negotiation that may be life changing for us. Luckily, people watching and identifying individual preferences has never been easier than it is today. The selfie generation is ultimately concerned with perception management. So the next time you negotiate take and post the best mental shot of yourself to the other party!

\section{References}

Cohen, B. (1980). You can negotiate anything. Bantam Books.

Fisher, R., \& Shapiro, D. (2006). Beyond reason. Using emotions as you negotiate. Penguin Books.

Fisher, R., Ury, W., \& Patton, B. ed. (2012). Getting to yes. Negotiating agreement without giving in. Random House Business Books.

Gallo, C. (2014). Talk like Ted. The 9 public speaking secrets of the world's top minds. Macmillan.

Lewicki, R. J., Saunders, D. M., \& Barry, B. (2011). Essentials of negotiation. McGraw Hill.

Shell, G., R. (2006). Bargaining for advantage. Negotiation strategies for reasonable people. Penguin Group.

Slocum, J. W., \& Hellriegel, D. (2011). Principles of organizational behavior. South-Western Cengage Learning.

Stone, D., Patton, B., \& Heen, S. (1999). Difficult conversations. How to discuss what matters most. Penguin Books.

Thompson, L. (2008). The truth about negotiations. Pearson Education Ltd.

Ury, W. (2015). Getting to yes with yourself (and other worthy opponents). HarperCollins.

\section{(cc) $\mathrm{BY}$}

This work is licensed under a Creative Commons Attribution 3.0 License. 